\title{
IMMEDIATE EFFECT OF KINESIO TAPING ON FUNCTIONAL ANKLE STABILITY AMONG MALE BASKETBALL PLAYERS
}

\author{
Mufa Wibowo \\ Aisiyah University at Yogyakarta
}

\begin{abstract}
BACKGROUND: Ankle injury frequently occurs in basketball players, which can lead to a functional ankle instability. The application of kinesio taping on ankle may increase functional ankle stability. However, to date immediate effect of kinesio taping application on functional ankle stability has never been studied. The study aimed to examine the immediate effect of kinesio taping on functional ankle stability among male basketball players.

SUBJECT AND METHODS: This was a quasi-experiment, before and after intervention with no control design. A sample of 15 male basketball players in Yogyakarta was selected for this study. The dependent was functional ankle stability (balance). The functional ankle stability was measured by Star Excursion Balance Test. The independent variable was kinesio taping application. The data was analyzed by paired t-test.

RESULTS: The functional ankle stability (mean $\pm \mathrm{SD}$ in $\mathrm{cm}$ ) before kinesio taping application was as follows: antero lateral 69.53 \pm 6.38 , antero medial $68.73 \pm 5.25$, and posterior $67.13 \pm 5.79$. Twenty minutes after application of Kinesio taping, the functional ankle stability (mean \pm SD) was as follows: antero lateral $72.07 \pm 6.16$, antero medial $71.33 \pm 5.26$, and posterior 69.60 \pm 5.44 . This increase in stability (balance) after application of kinesio taping was statistically significant $(\mathrm{p}<0.001)$.

CONCLUSION: The application of kinesio taping can immediately increase functional ankle stability among male basketball players.
\end{abstract}

Keywords: kinesio taping, functional ankle stability, Star Excursion Balance Test 